\title{
Evaluation of Phase One Scan Station for Analogue Aerial Image Digitisation
}

\author{
Joachim Schulz ${ }^{1}$ Michael Cramer ${ }^{1}$ (1) $\cdot$ Theresa Herbst $^{2}$
}

Received: 28 July 2021 / Accepted: 1 August 2021 / Published online: 5 November 2021

(c) The Author(s) 2021

\begin{abstract}
Historical aerial photographs represent a special cultural asset for preserving information about land cover and land use change in the twentieth century with a high spatial and temporal resolution. A current topic is the digitisation of historical images to make them accessible to a wider range of users and to preserve them from age deterioration. For a photogrammetric evaluation, a high geometric stability and accuracy during the digitization process is required. In this work, the resolving power and geometric quality of a Phase One iXM-MV150F high-performance camera was investigated, which is used at the Landesamt für Geoinformation und Landentwicklung Baden-Württemberg in the project 'Digitaler Luftbildatlas Baden-Württemberg' for the digitisation of historical aerial photographs. The resolving power of the system was empirically measured and analysed. The required modulation transfer function was determined using Siemens stars. With this method, the significant influence of the focus setting and deviations of the plane-parallel alignment could be determined. Using a digitised aerial survey of the Vaihingen/Enz test field, the impact of the above-mentioned effects and the influence of the geometry of the scanning camera on the quality of the derived data products was shown in comparison to a photogrammetric scanner. The comparison showed that dedicated photogrammetric scanners still achieve a higher accuracy, even if a high-quality optical system is used for the digitising stand with the document camera. Further investigations are justified to improve the accuracy and stability of digitising the aerial image with a document camera.
\end{abstract}

Keywords Historical images · Digitisation · Phase one $\cdot$ Viewshed

\section{Zusammenfassung}

Evaluierung der Phase One Kamera zur Digitalisierung historischer Luftbilder. Historische Luftbilder stellen ein besonderes Kulturgut dar, um Informationen über Landbedeckung und Landnutzungsänderung im 20. Jahrhundert mit hoher räumlicher und zeitlicher Auflösung zu erhalten. Ein aktuelles Thema ist die Digitalisierung historischer Bilder, um sie einem breiteren Nutzerkreis zugänglich zu machen und sie vor dem Verfall zu bewahren. Für eine photogrammetrische Auswertung ist eine hohe geometrische Stabilität und Genauigkeit während des Digitalisierungsprozesses erforderlich. In dieser Arbeit wurde das Auflösungsvermögen und die geometrische Qualität einer Phase One iXM-MV150F Hochleistungskamera untersucht, die am Landesamt für Geoinformation und Landentwicklung Baden-Württemberg im Projekt 'Digitaler Luftbildatlas BadenWürttemberg' zur Digitalisierung von historischen Luftbildern eingesetzt wird. Das Auflösungsvermögen des Systems wurde empirisch bestimmt und mit der Modulationsübertragungsfunktion auf Basis von Siemenssternen visualisiert. Mit

Joachim Schulz

joachim.schulz@alumni.uct.ac.za

Michael Cramer

michael.cramer@ifp.uni-stuttgart.de

Theresa Herbst

theresa.herbst@lgl.bwl.de

1 Institut für Photogrammetrie (ifp), Universität Stuttgart, Stuttgart, Germany

2 Landesamt für Geoinformation und Landentwicklung Baden-Württemberg (LGL BW), Stuttgart, Germany 
der Methode konnte der signifikante Einfluss der Fokuseinstellung und Abweichungen der planparallelen Ausrichtung ermittelt werden. Anhand eines digitalisierten Luftbildverbands vom Testfeld Vaihingen/Enz wird die Auswirkung der oben genannten Effekte und der Einfluss der Geometrie der Dokumentenkamera auf die Qualität der abgeleiteten Datenprodukte im Vergleich zu einem photogrammetrischen Scanner gezeigt. Der Vergleich zeigt, dass photogrammetrische Scanner eine höhere Genauigkeit als die Phase One Kamera erreichen, auch wenn für den Digitalisierstand mit der Dokumentenkamera ein hochwertiges optisches System verwendet wird. Weitere Untersuchungen sind gerechtfertigt, um die Genauigkeit und Stabilität der Digitalisierung von Luftbildern mit einer Dokumentenkamera zu verbessern.

\section{Introduction}

The digitisation of historical aerial photographs requires a high geometric quality, as the geometry of the original images should be preserved and (almost) not be influenced by the scanning process. Therefore, the (historic) photogrammetric scanners were carefully designed and investigated to avoid any kind of distortion. The scan station based on the Phase One iXM-MV150F camera which is investigated here represents a new concept of scanning, where the scan is taken instantaneously with one shoot only. This concept is known from document scanning but not yet widely implemented in the photogrammetric world. In this paper, the geometric performance of such scan station is investigated and compared to traditional photogrammetric scan solutions.

\subsection{Motivation}

Photogrammetric products such as aerial images, processed orthophotos, and extracted 3D information from digital images have been used for a long time in many disciplines and are regarded as a staple source of geoinformation. Official aerial photographs are largely captured at sub-metre, mostly decimeter resolutions, with stereoscopic coverage and taken at regular time intervals. In addition, many parts of Germany and Baden-Württemberg were recorded in aerial reconnaissance flights during and after the Second World War. Historical aerial photographs in general represent a unique cultural asset to obtain information on land cover and land use during the last century with a high spatial and temporal resolution. Aerial images are used to facilitate long-term environmental monitoring studies and change detection based on the analysis and evaluation of time series of images, or to calculate 3D information from the aerial photographs photogrammetrically. However, not least the digital availability of historical data is still a major hurdle, as the majority is currently stored in analogue form and would have to be searched in governmental archives before being digitised on a case-by-case basis (Cowley and Stichelbaut 2012). As of today, the National Mapping Agencies (NMAs) of the 16 states of Germany have about 4.5 million historic analogue airborne photogrammetric images in their archives. About half of them are currently not digitised.
For this reason, the inclusion of historical data into current research projects involves a considerable amount of extra work. However, a recent report by EuroSDR (Giordano and Mallet 2019) shows that the added value of digitised archives has been recognised and more countries are in the process of developing digitisation strategies to digitise their aerial photo archives, in some cases to process them into further photogrammetric products and to offer them to a wider group of users.

In addition, the correct storage of all these analogue images plays an important role. Quite often, even in the NMAs' archives, the film materials are stored under normal environmental conditions, without temperature and humidity control. This accelerates the ageing process of the film or even damages the film, due to chemical processes and compounds breaking down in the film materials. Furthermore, problems are also caused by the protective sleeves in which the film negatives or positives were originally placed to protect them from damage. These sleeves are often made from paper, folded at the edge and glued. Over time, the glue reacts with the film and can cause further damage. The labelling of the sleeves was also done with felt pens, which also reacts with the film over time. In addition, bacteria and fungi can settle on the silver iodine layer of the film and destroy it.

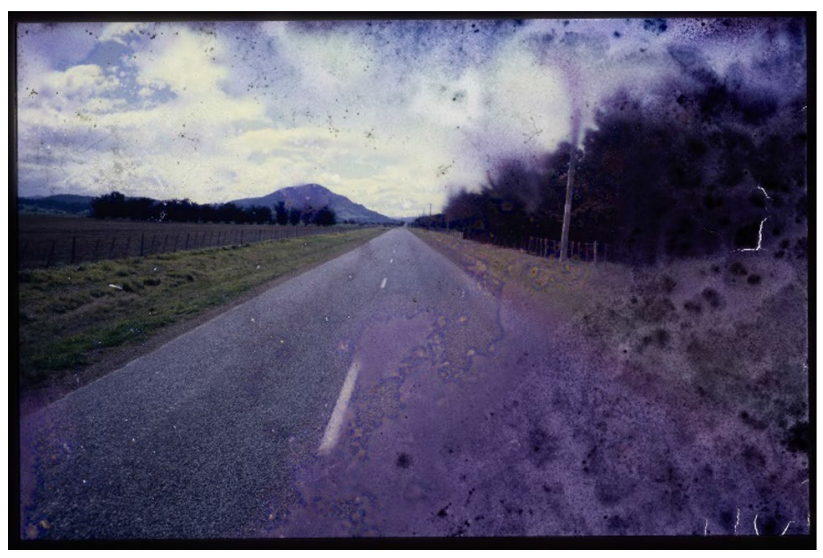

Fig. 1 Example of a badly deteriorated $35 \mathrm{~mm}$ diapositive film. Bacterial growth on the film layer have damaged large parts of the film resulting in loss of information 
An example of bacterial growth and damage to the film layer can be seen in the diapositive film in Fig. 1.

Considering the estimated remaining lifetime of aerial photographs and suboptimal archiving conditions, current estimates suggest that the digitisation process should be completed within the next 10-15 years to minimise irreversible loss and film deterioration (Aleithe 2021).

In Baden-Württemberg, the project "Digitaler Luftbildatlas Baden-Württemberg" (DLBA) was established at the Landesamt für Geoinformation und Landentwicklung Baden-Württemberg (LGL-BW) as part of the state's digitisation strategy 'digital@bw' to digitise large parts of the analogue aerial photo collection to protect them from agerelated chemical decay and to process them into historical orthophotos (Herbst 2020). This project was the reason for investing in this scanning station to be able to digitise the analogue photogrammetric images efficiently.

\subsection{Photogrammetric Scanners (1st Generation)}

The development towards digital photogrammetry in the 1980s and 1990s created the need to scan analogue aerial photographs for further digital processing. To transfer the geometric quality of a photogrammetric film to the digital copy, a high geometric stability and accuracy was required in the scanning process, as all subsequent processing steps and products refer back to the derived digital copy (Kraus 2007). The use of specialised photogrammetric scanners became an essential part of the photogrammetric workflow at that time and the established procedure for aerial image digitisation (Baltsavias 1999). In addition, resolution, radiometric and geometric accuracies were extensively tested and verified in scanner studies (Baltsavias et al. 1997; Baltsavias 1998, 1999; Baltsavias and Kaeser 1999).

In addition, special close-range scanners (comparators) for the automatic measurement of signalised points in analogue films were developed for industrial photogrammetry tasks (Fraser and Brown 1986; Luhmann and Wester-Ebbinghaus 1986). These systems realised geometric accuracies better than $1 \mu \mathrm{m}$. Possible unflatness of the original film was corrected using an additional reseau grid technique.

Photogrammetric scanners have also been compared to so-called non-photogrammetric scanners, such as flatbed desktop publishing scanners (Baltsavias and Crosetto 1996; Baltsavias and Waegli 1996). These scanners were not manufactured for the specific use case of scanning aerial images. The major conclusion at the time was that the geometric accuracy of commercial DTP scanners was a major limiting factor in their suitability for photogrammetric scanning compared to dedicated photogrammetric scanners.

All large photogrammetric system suppliers at that time offered dedicated photogrammetric scanners. The scanning of the original images was done patch-wise. Patches were referenced to each other to form the final large format scanned image. With special components like linear encoders and careful calibration methods the generally proposed geometric RMS range of these systems was around $2 \mu \mathrm{m}$. Scanners like the ZI-Imaging PhotoScan, Leica Geosystems DSW700, Vexcel Imaging Ultrascan5000 and the Wehrli RM-3, RM-6 scanners are examples of this first generation of photogrammetric scanners. Except for the Wehrli RM-6, all other scanners are not manufactured any more, as the need for photogrammetric scanners has since then drastically declined due to digital aerial cameras becoming standard in the production and processing of aerial photographs. It is interesting to note, that even though the systems are more than 20 years old by now, a few of them are still available and (partly) in operation at German mapping agencies. An internal survey of the state mapping agencies in Germany identified four scanners from ZI-Imaging (SCAI), three from Leica (DSW600/700), five from Vexcel (UltraScan5000) and one Wehrli (RM-3a) scanner that are currently still in use (Herbst 2021). For example, the LGL-BW has used the photogrammetric high-performance scanner "UltraScan5000" from Vexcel for photogrammetric digitisation work. Using a push-broom linear array and an integrated self-calibration procedure, it offers high geometric accuracy together with high radiometric performance and high image sharpness (Vexel 2008). These 1st generation photogrammetric scanner systems in general are still serviced by the manufacturers and a second-hand market still exists. Nonetheless, such scanners are very delicate and need frequent maintenance, which is why high maintenance costs would have to be anticipated. In addition, the manufacturer is no longer in the market, which could make repairs difficult and costly.

\subsection{Current Scanner Developments}

A new camera-based method for digitising aerial images, originally from the field of reproduction photography for, among other things, book digitisation and digitisation of art and cultural heritage, is also being used in some surveying administrations and state aerial image archives (Herbst 2020).

In these fields, the recording camera, is often attached to a height-adjustable tripod and captures images from a top view. Such a system is often referred to as a document scanner or document camera. While images that are digitised with classic scanners are either scanned by combining several partial images or line by line, digitisation with the document camera is carried out by taking a single picture of the analogue aerial image. This "one frame-one image" concepts circumvents any kind of image stitching later and, 
thus, is preferred by many customers. Besides this, the much faster scanning process is the main advantage of scanners based on this frame imaging technology.

The project at the LGL-BW uses a Phase One iXMMV150F high-performance camera combined with an HR Digaron-SW float $138 \mathrm{~mm} \mathrm{f} / 6.5$ lens. A light table provides a diffuse white light source to shine through the historic aerial image. Like all camera-based systems, the camera will deviate from the idealised pinhole camera principle. Distortions and other effects arise and are combined with the inherent distortions already present in the analogue image. Another influence on the digital images is related to the resolution potential which, together with a non-optimal focusing and parallel alignment of the sensor and image plane, could lead to deviations between the effective resolution and the nominal resolution.

Other German mapping agencies have also invested in such a system or similar systems, like the NMAs of the state of Bavaria and Lower Saxony, with others also interested. In other European countries, similar systems have also been implemented. The NCAP (National Collection of Aerial Photography) in the UK use DSLR and medium-format digital cameras to produce digital surrogates in archival quality to reduce handling (NCAP 2021). The IGN (National Institute of Geographic and Forest Information) in France presented a system during a EuroSDR Workshop on geoprocessing and archiving of historical aerial images (Truquin 2019).

Kalinowski et al. (2021) used a professional grade DSLR camera with a macro lens to digitise historic glass plates. The images have subsequently been used in combination with modern data to create a photogrammetric reconstruction of the archaeological survey site. By calibrating the digitisation camera and creating distortion-free images, influences such as lens distortion were corrected. Due to the age of the glass plates however, no technical information of the original camera has survived. The effect of calibrating the digitising camera and removing image distortions could, therefore, not be independently verified in the scope of their project.

These examples show that camera-based systems are already used to digitise historic aerial images with the intention of extracting photogrammetric information that requires a high degree of geometric accuracy. There are different solutions which are based on the Phase One iXM 100MPix or 150MPix cameras, other providers like GeoDyn PromptSCAN combine up to six industrial cameras to cover the large film format in different colour bands (GeoDyn 2021). Performance evaluations of such systems have, to the best of our knowledge, not yet been published. Therefore, an investigation into the quality of the Phase One digitisation system can be relevant to obtain first indications of the performance regarding the spatial resolution and accuracy of the system.

\section{Digitaler Luftbildatlas Baden-Württemberg (DLBA)}

The aerial photograph collection at the LGL-BW is a unique cultural asset. In addition to the digital aerial photographs, it includes a stock of about 400,000 analogue aerial photographs from the years 1934 to 2008. In a 5-year cycle, the complete land cover of Baden-Württemberg was documented from 1968 to 2008. From 2009 onwards, the state is surveyed digitally in a 3-year cycle.

Some analogue aerial photographs were identified which have already been damaged by chemical degradation. It was, therefore, decided to digitise large parts of the collection with a quick and efficient method as it is time-critical to limit effects of further decay. By digitising the collection, valuable originals can be secured for future generation and make the historical data more accessible at the same time. For this reason, the state government has initiated the DLBA project to be tasked with digitising the historical images. Subsequently, selected aerial photographs will be georeferenced and rectified, and historical, area-wide, digital orthophotos (DOPs) of BadenWürttemberg will be created. A positional standard deviation of $2 \mathrm{~m}$ horizontal and $3 \mathrm{~m}$ vertical is envisaged for the oriented aerial images used for the orthophoto production.

The question of how to digitally transform the existing, individual polyester films effectively had to be clarified too. Usually, the digitisation of analogue aerial photo negatives is done with a photogrammetric scanner. The advantages of the photogrammetric scanner are, however, offset by difficulties for "mass production" at this scale. The digitisation process of an aerial image would take about $15 \mathrm{~min} /$ image using a $1 \mathrm{st}$ generation photogrammetric scanner.

It was, therefore, important to invest in a system that is cost-effective and keeps loss of photogrammetric quality to a minimum. A new technology, a high-performance camera, was tested in cooperation with the Bavarian Agency for Digitisation, High-Speed Internet and Surveying (Landesamt für Digitalisierung, Breitband und Vermessung). Comparisons of images from both systems showed that the quality and a resolution of $\approx 22.5 \mu \mathrm{m}$ were sufficient for our project. A 150-megapixel camera from the company Phase One was chosen. With this high-performance camera (Fig. 3), the analogue aerial photographs can be digitised within a few seconds with sufficient resolution. There are also lower maintenance costs with this technology. By using a tripod and selecting an optimal lens, it would also be possible to digitise a variety of formats such as maps or plans. A survey 
in 2021 involving all state mapping agencies in Germany showed that more and more federal states are planning to use a camera system for their digitisation work (Herbst 2021). So far however, there are very few institutions that digitise their analogue aerial photo stock with the help of a camera. This interest and need to examine the camera system for photogrammetry motivated an empirical investigation of the resolution and geometric accuracy in a master thesis at the Institute of Photogrammetry at the University of Stuttgart (Schulz 2021), from which results are included in this paper.

Before each aerial photograph is digitised, any known metadata is recorded. The standards of the working group of the state surveying agencies (Arbeitsgemeinschaft der Vermessungsverwaltungen der Länder und der Bundesrepublik Deutschland AdV) are also considered. Each aerial photograph is given a unique name, camera parameters are added, and the image centres are calculated.

After the digitization is complete, orthophotos are derived from the images. The work is focussed on the aerial photographs from the 5-year cycle of which DOPs can be created. Together with other orthophotos, time slices of different aerial image epochs can be displayed and compared. In addition, with orthorectification, the historical aerial photographs can be made more usable and available to the public, economy, administration, and science via the Geoportal Baden-Württemberg and by means of spatial data services. The individual digital copies and products, together with the metadata, are transferred to a database. Customer enquiries can thereby be processed quickly in the future.

Figure 2 shows the current state of processing and availability of the orthophotos at the LGL:

- Road data flight from 1968 which was produced by the Landesarchiv Baden-Württemberg (blue).

- "1. Tranche" (1986-1990) in yellow.

- Six coverages (1998-2017) in orange.

After completion of the second processing tranche (1976-1980), the area of Baden-Württemberg can be mapped first every 10 years, then every 5 years and finally every 3 years. Subsequently, the years 1981-1985 will be processed.

The orthophotos can be viewed as time slices in the Geoportal BW. In addition, they can be implemented as a WMS service in a GIS while their year layers can be individually

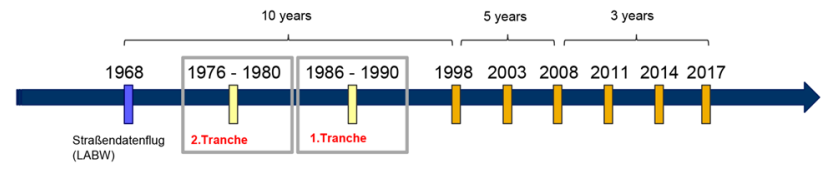

Fig. 2 Overview of tranches, which are processed within the DLBA project

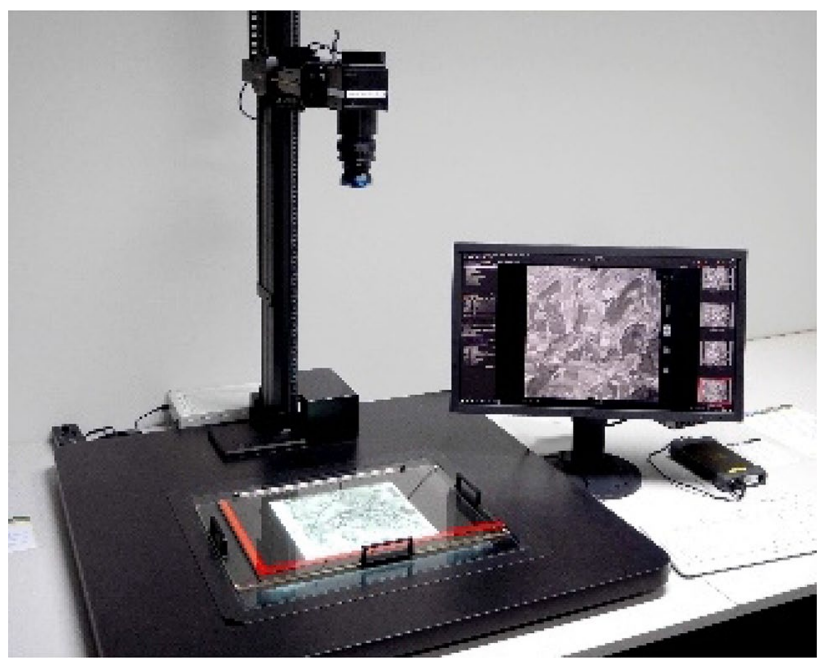

Fig. 3 Digitisation station used for the DLBA Project

selected. With the help of a time slider, time series analyses from different epochs can also be carried out. Changes in the landscape, for example during urban planning processes, can be analysed interactively over decades. Analyses of changes such as agricultural and forestry use, changes in vegetation or the identification of former industrial facilities provide information on land use changes. The comparability of historical aerial photographs from different eras enables planning, cost, and legal certainty for municipalities and specialised authorities in the state. A fusion with additional spatial data from other agencies also creates added value for business, administration, and scientific research.

\section{Digitisation Station}

The components of the digitisation stand are a Phase One camera sensor with Rodenstock lens that is attached to a height-adjustable copy stand. The shooting height is adjustable by means of a stepper motor on the tripod and is set such that the dimensions of an aerial photograph $(23 \mathrm{~cm} \times 23 \mathrm{~cm})$ are reproduced in a single shot. Dust and other particles are removed from the photograph before it is placed on a light table and illuminated from below. To ensure the flatness of the film, a glass cover is placed on top. The square film format of a traditional aerial photograph means that the complete sensor area is not used. The edge area is, therefore, not needed, and the image is cropped to the reduced dimensions automatically after capture.

The medium-format achromatic sensor of the Phase One camera captures a grey-scale image. The main advantage of using an achromatic sensor is that the resolution is not reduced by a colour filter (Bayer pattern) and that chromatic 
aberrations are only introduced as blur. A disadvantage is, of course, that the spectral resolution is reduced to one channel. Full colour capturing is, therefore, currently not possible and analogue colour photographs would be digitised as grey-scale images. The choice of sensor, therefore, involved a trade-off between resolving power and radiometric resolution. Since historical aerial photographs were mostly captured with panchromatic film, better spatial resolution is estimated as more important than the potential to capture RGB radiometry.

The aerial photographs are digitised using the high-performance camera as seen in Fig. 3. To reduce projective distortion, the sensor plane must be aligned parallel to the light table/capture plane. To ensure that both planes are parallel, a mirror is placed on the light table and the lens is focussed onto its own image in the mirror. Is the camera exactly perpendicular to the light table, the mirror image of the camera would be exactly in the centre of the image. If a slight tilt of the camera is present, the mirror image is off-centre and the camera has to be aligned with adjusting screws. Whilst this method is effective to check and to adjust the correct positioning, the focus must be adjusted and forces a new focus adjustment every time the check is performed.

\section{Concepts and Models}

\subsection{Resolution and Resolving Power}

Resolution is defined in the German standard DIN 18716 (DIN 2017) as the ability of a sensor system to detect signals from adjacent object structures separately. Targets such as the USAF1951 test target are popular and often used when determining the resolving power of an imaging system. They are, however, dependent on subjective components such as the display, viewer's choice to determine which bar target is still discernible and are arranged with discrete spacing.

An objective approach to determine the resolving power based on empirical measurements was, therefore, chosen. The modulation transfer function (MTF) is measured using a new software that has been developed in the scope of a doctoral thesis (Meißner 2021) and will form part of a new DIN Norm regarding image quality requirements (Cramer et al. 2020). The MTF at 10\% modulation contrast (MTF10) is used to determine the resolving power in image space. The link to the relevant object space is established by multiplying the factor $\frac{1}{\text { MTF10 }}$ to either the nominal pixel resolution of the camera, or to the GSD (Meißner 2021). Therefore, the effective scan resolution and ground resolving distance (GRD) can be determined respectively.

\subsection{Camera and Lens Model}

In photogrammetry, the fundamental model is based on the ideal pinhole camera. The central projection and extended collinearity equations describe the perspective transformation between object space (object point $X, Y, Z$, perspective centre $X_{0}, Y_{0}, Z_{0}$ and camera attitude $\boldsymbol{R}$ ) with image space (image point $\left.x^{\prime}, y^{\prime}\right)$ :

$\left(\begin{array}{c}X \\ Y \\ Z\end{array}\right)=\left(\begin{array}{c}X_{0} \\ Y_{0} \\ Z_{0}\end{array}\right)+m \boldsymbol{R}(\omega, \phi, \kappa)\left(\begin{array}{c}x^{\prime}-x_{0}^{\prime}-\Delta x \\ y^{\prime}-y_{0}^{\prime}-\Delta y \\ -c\end{array}\right)$.

By performing a camera calibration, the unknown parameters of the exterior and interior orientation (principal point coordinates $x_{0}^{\prime}, y_{0}^{\prime}$, principal distance $c$ and systemic departures from collinearity due to image distortion of real cameras, $\Delta x$ and $\Delta y$ ) are solved (ISO 19159-1:2014, Annex C.2).

The de-facto standard camera model in close-range photogrammetry by Brown $(1966,1971)$ has been used to calibrate the mentioned interior orientation parameters and lens distortions (radial and tangential distortion). This camera model has been widely adopted in commercial and scientific photogrammetry software such as Agisoft Metashape or Photometrix Australis. The benefits of the camera calibration are two folds. With a calibration of the camera under laboratory conditions, the quality of the lens can be investigated. By calibrating the camera directly on the copy stand, in situ camera parameters can be refined to obtain geometrical corrections that are directly associated with the recording configuration used on the job. Distortions attributed to the digitising camera can then be removed in the digitised aerial images.

Furthermore, the widely implemented 12- and 44-parameter mathematical models by Ebner (1976) and Grün (1978) have been used to introduce additional correction parameters (APs) during aerotriangulation (AT). Additional parameters are generally used to compensate residual systematic errors that remain in the images used in the AT.

The thin lens equation, which can be found in reference textbooks such as Luhmann et al. (2020) and Pedrotti et al. (2005), links the focal length $f^{\prime}$ to the object distance $a$ and image distance $a^{\prime}$ :

$\frac{1}{a^{\prime}}+\frac{1}{a}=\frac{1}{f^{\prime}}$.

The nominal focal length of a lens approximates the image distance (calibrated focal length) only when focused to infinity (Luhmann et al. 2020). As the camera is capturing with a scale of 1:6 (Table 1), the lens is focused on the near end of its range. As the principal distance approximates the image distance, this close focus must be considered when interpreting the results of the in situ camera calibration. 

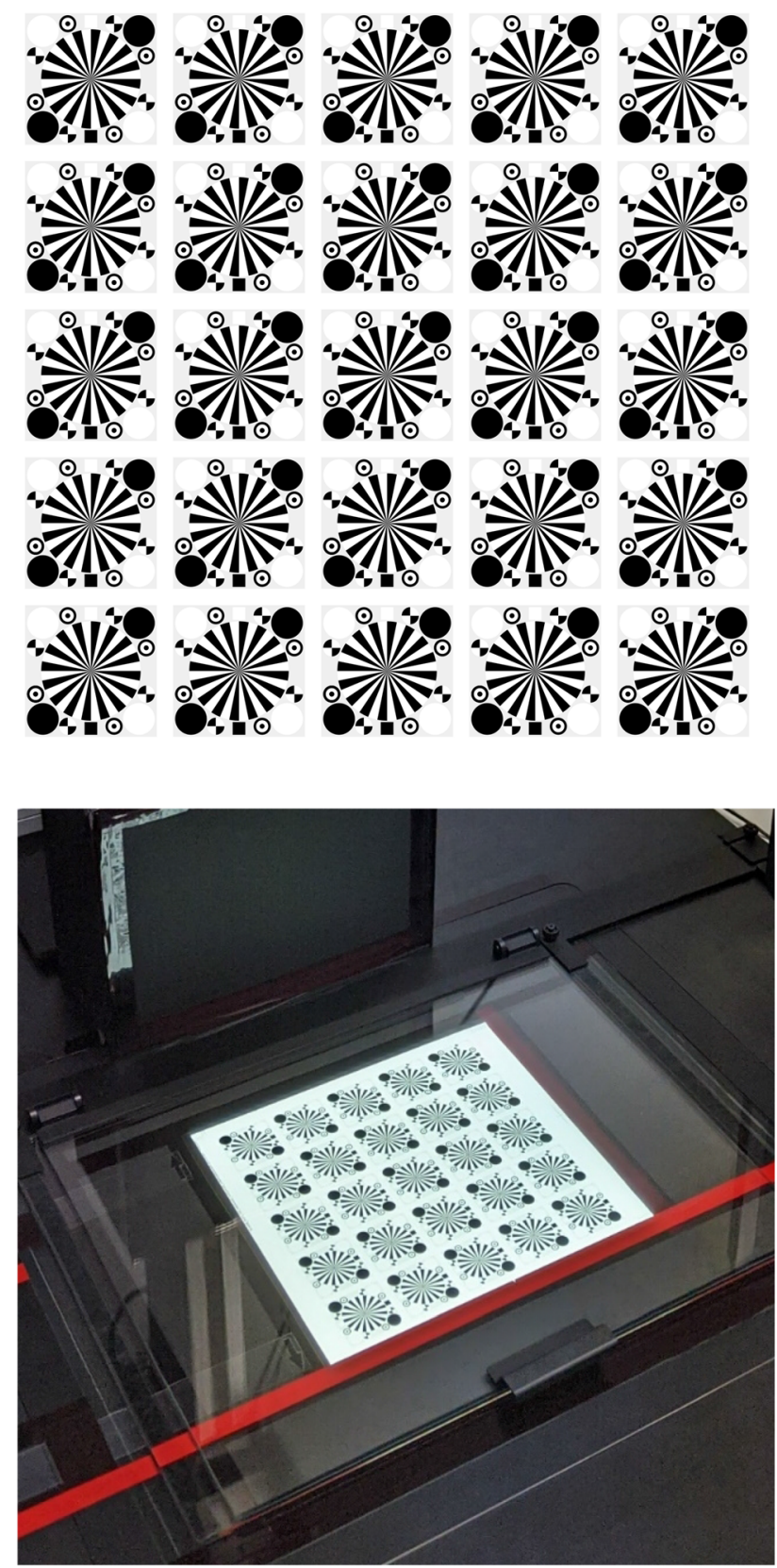

Fig. 4 Siemens stars arranged as a $5 \times 5$ resolution pattern (above). Example of the resolution pattern being imaged (below)

\section{Evaluation of Geometric Resolution}

For the analysis of the resolution, a template (Fig. 4) was developed based on a provided vector graphic of a Siemens star. A total of 25 Siemens stars were arranged in a regular grid structure to determine the resolving power of uniformly distributed samples within a single image.

The nominal pixel resolution (Table 1) was determined with a simple scale calculation using calibrated distances between grid markers of a reseau grid. Converted, this
Table 1 Technical specifications for the digitization station at LGLBW

\begin{tabular}{ll}
\hline Parameter & Value \\
\hline Camera sensor & Phase One iXM-MV150F \\
Sensor dimensions & $53.41 \mathrm{~mm} \times 40.05 \mathrm{~mm}$ \\
Pixel resolution & $150 \mathrm{MP}(14,204 \mathrm{~mm} \times 10,652 \mathrm{~mm})$ \\
Pixel size & $3.76 \mu \mathrm{m}$ \\
Cropping factor & 0.648 \\
Channels & 1 \\
Lens & Rodenstock HR Digaron-SW float $138 \mathrm{~mm} \mathrm{f/6.5}$ \\
Focal length & $138 \mathrm{~mm}$ \\
Equivalent focal & $90 \mathrm{~mm}$ \\
length (35 mm) & \\
Image circle & $110 \mathrm{~mm}$ \\
Aperture & 6.5 \\
Depth of field & $\approx 3 \mathrm{~mm}$ \\
Nominal resolution & $22.7 \mu \mathrm{m}$ \\
Image scale & $\approx 1: 6$ \\
\hline
\end{tabular}

nominal capture resolution is, therefore, approximately 1120 ppi. Compared to this, the resolution of the physical Siemens stars needs to be reproduced to a significant higher resolution to serve as reference for the evaluation of the absolute scanner resolution, i.e. the resolution of the reference Siemens stars must be much higher than the nominal 1120 dpi resolution. Due to the high resolution required for this application, a film exposure service was used to produce the see-through film with a quoted resolution of $3657 \mathrm{dpi}$ (Kopp 2021).

It must be mentioned that the realisation of such a reference target is not trivial and associated with high requirements regarding the print quality. In Fig. 5, an exemplary Siemens star centre of three different reference targets is shown at identical magnification. All targets shown were manufactured with processes that should achieve a higher resolution than the cameras imaging resolution. The first image shows a Siemens star centre that is unusable for the determination of resolution, due to prominent artefacts and

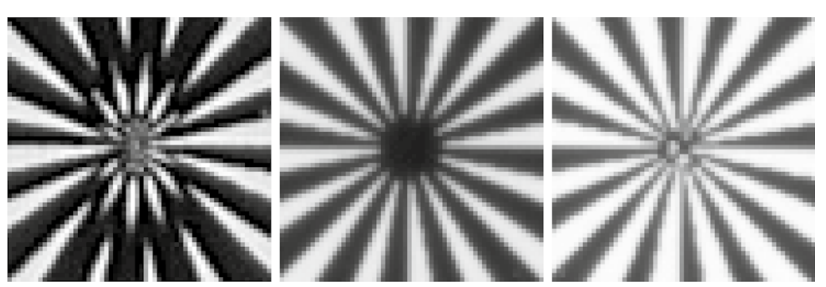

Fig. 5 Imaged Siemens star centres of different quality. The first image shows a centre of a Siemens star that is unsuitable to measure resolution. The middle target has a large centre circle that limits detection of the absolute resolving power. The last image shows a better print from the same service provider as the middle Siemens star 
sectors merging irregularly. The second image clearly shows, in comparison to the third Siemens star, that the resolution of the physical target is lower, due to the larger size of the blur circle. The resolution of this target could, therefore, lie below that of the camera. Whilst this concern cannot be completely eliminated in the Siemens star shown in the third image, the blur circle is significantly smaller. The last two examples were produced by the same provider to the same quoted manufactured resolution of $3657 \mathrm{dpi}$ which seems to be a bit optimistic. Unfortunately, the improved reference target shown in the last image of the figure was not available for a long-term comparison.

Whilst the second target would not be suitable to measure the absolute resolving power of the camera, as the target resolution limits the measurements, it was able to detect relative changes in sharpness between epochs as seen in Fig. 6. Future work will cover a repetition of the long-term measurements using the improved resolution target.

\subsection{Determination and Visualisation of Resolving Power}

The MTF10 obtained at each sample is applied to the nominal size of the scanning pixel to determine the resolving power in object space. Using interpolation surfaces generated from the MTF10 measured with each star, the achieved

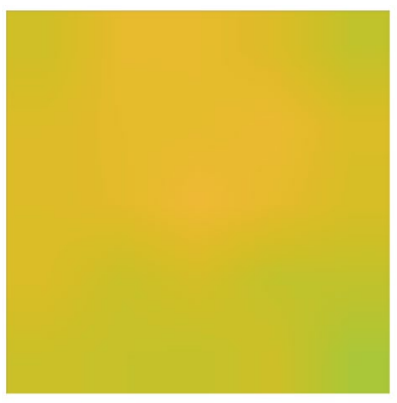

September 2020

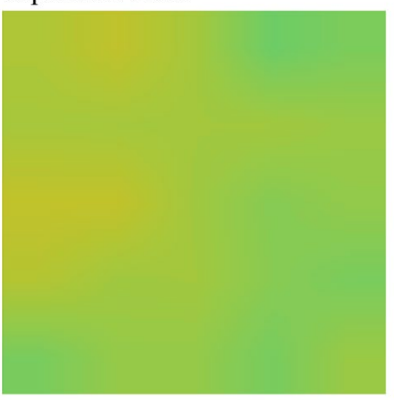

March 2021

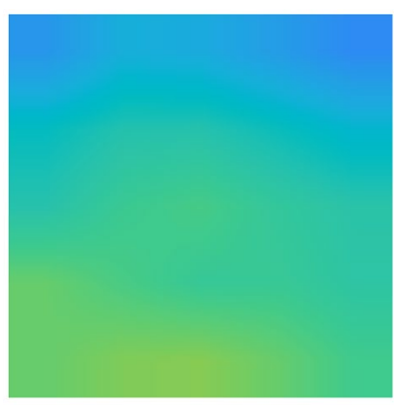

February 2021

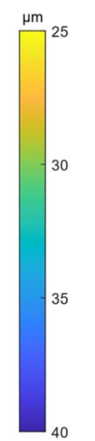

Fig. 6 Interpolated resolution surfaces of long-term comparisons. Three different epochs shown: September 2020, February 2021 and March 2021 resolving power was compared over three epochs captured a few months apart, as seen in the Fig. 6 .

The stability of the set-up is an important criterion for recording the analogue aerial photographs with an expectable and reproducible quality over longer periods of time. If images are digitised with suboptimal capturing parameters, the resulting loss of resolution cannot be regained after the scan. The resolving power was, therefore, measured and used to find relative changes over the course of a few months between September 2020 and March 2021. The first sample (September 2020) in Fig. 6 represents the measured optimum over the study period, as it shows the best results obtained with the Siemens stars used. Between the picture taken in September 2020 and February 2021, the camera was taken off the copy stand and subsequently refocused. The last image from March 2021 was taken after again refocusing the lens to improve the focus.

The second measurement in the figure (February 2021) shows a measured resolution that is significantly below the first reference measurement and not uniformly distributed. The resolution of the third test (March 2021) comes close to that of the reference but does not reach it.

The comparison shows that finding the optimal focus manually is not trivial and a dominant factor for the difference in image sharpness across the measurements, mainly due to the limited depth of field available. Additionally, a directional change in resolution could also indicate that the camera is no longer optimally aligned and that the parallelism of sensor and object plane needs to be checked and adjusted if necessary. Both findings underline that the quality of the system is limited by the quality and repeatability that can be achieved of the manual adjustments. Since the focus adjustment is done purely manually, care and experience during the adjustment are critical and a major factor during calibration that significantly influence the final scan quality.

\subsection{Comparison of Spatial Resolution in Aerial Images}

The above results referred to the resolving power under laboratory conditions. It is, however, also of interest, how resolving performance performs in digitised real aerial photos in comparison with scanners of the 1 st generation.

In 2008, the Vaihingen/Enz test field (see Sect. 6.3) was used in an extensive aerial camera evaluation project by the DGPF. The project included a Siemens star placed in the environment and captured during the aerial survey (Cramer 2010). The analogue reference film of this project was digitised again using the Phase One digitisation station, thereby allowing direct comparisons with the traditionally scanned digital images of the analogue film using the Z/I Imaging 
Table 2 Scanning parameters

\begin{tabular}{lll}
\hline Digitisation method & Digitisation station & $\begin{array}{l}\text { Z/I imaging Photoscan } \\
2001\end{array}$ \\
\hline Sensor type & Achromatic 2D sensor & Trilinear CCD sensor \\
Size of scan pixel & $22.7 \mu \mathrm{m}$ & $14 \mu \mathrm{m}$ \\
Image resolution & $1120 \mathrm{ppi}$ & $1800 \mathrm{ppi}$ \\
GSD & $13 \mathrm{~cm}$ & $8 \mathrm{~cm}$ \\
Colour channels & Greyscale (1 channel) & RGB (3 channels) \\
Bit depth & 8 bits (export) & $3 \times 8$ bits \\
\hline
\end{tabular}

Photoscan 2001. The different scan settings can be seen in Table 2.

The Siemens star has been captured in a total of $n=15$ images during flight, in which the spatial resolution in object space could, therefore, be determined. In contrast to the previous investigation, this evaluation refers to the entire system, consisting essentially of the analogue aerial camera and the digitisation method. Since both cases involve the same film and differ only in the digitisation method, it is possible to examine how the digitisation method affects the resolution.

In contrast to the laboratory study of the document camera, where the position of the Siemens star in the image is freely selectable and multiple samples were obtained in a single image, the position in the aerial image is fixed by the acquisition of the analogue aerial image. The results in Fig. 6 show that the resolving power can vary in the investigated image area of the digitisation camera. For any camera, including the aerial camera, the resolving power generally decreases radially from the centre of the image, due to light fall off which decreases contrast and due to blur introduced by chromatic and spherical aberrations (Kraus 2007). The results are, therefore, categorised relative to their position in the aerial image. The aerial image was subdivided into the areas image border, image field and image centre to show this effect.

The resolution of each colour channel of the photogrammetrically scanned images is reduced to an average value to facilitate a better comparison with the grey-scale images from the document camera. Figure 7 shows the spatial resolution of the digitised images. In both cases, the resolution at the edge of the image is slightly lower than in the centre of the image, as it can be expected. This effect appears to be more pronounced with the document camera, probably due to the overlapping radial dependence of resolving power of both the aerial RMK-Top15 and the digitising camera.

The evaluation of resolution from aerial images shows that the performance currently does not reach a similar performance as a photogrammetric scanner. The spatial resolution in the digitised aerial image differs significantly from the nominal ground resolution. The resolved ground pixel

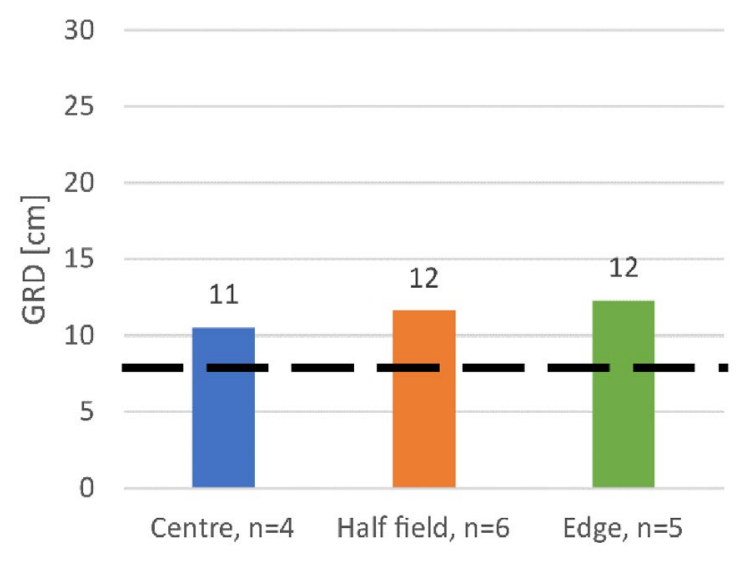

Z/I Imaging Photoscan 2001 - resolved ground pixel (GRD) w.r.t. location of the Siemens star in the aerial photograph. The nominal GSD is $8 \mathrm{~cm}$.

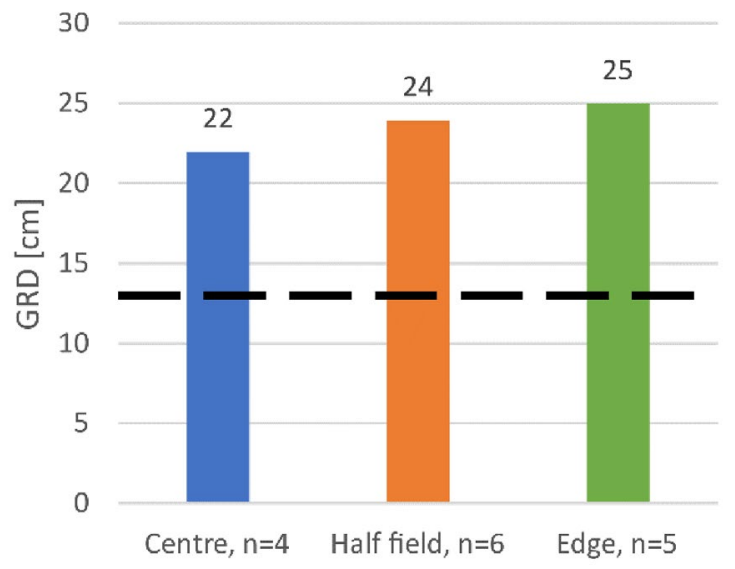

Phase One iXM-MV150F (achromatic) - resolved ground pixel (GRD) w.r.t location of the Siemens star in the aerial photograph. The nominal GSD is $13 \mathrm{~cm}$.

Fig. 7 Comparison of the spatial resolution

with the scanner is between $\sim 30$ and $\sim 55 \%$ greater than the nominal resolution. Digitised with the document camera, the GRD deviates between $\sim 70$ and $\sim 90 \%$ from the GSD. At the edge of the image, the actual resolution is almost twice as large as the GSD suggests.

This does not necessarily mean that the difference is always as pronounced as in this digitised example or purely inherent to the camera and lens combination. A major contribution to a poor ground resolved distance can be attributed to suboptimal conditions during the digitisation process, such as a defocussed lens as seen in Fig. 6. These results do, however, confirm the need to check the sharpness and resolution of the system regularly. The lens can then be refocused accordingly if significant deviations are detected. 


\section{Camera Calibration and Evaluation of Geometric Accuracy}

\subsection{Lab Calibration}

A camera calibration under laboratory conditions with a fixed test field that includes depth variations, confirmed the high quality of the lens. Inevitably, the calibration had to be performed with a different camera focus and aperture settings to accommodate for the different working distance and to increase depth of field when recording convergent images of the test field. Furthermore, the lens had to be combined with another camera body from the same camera series, as the body used in the scan station was not available for the calibration laboratory.

The radial distortion reaches a maximum of $\approx 3$ pix with the tangential distortion being around $\approx 0.2$ pix at its maximum (Schulz 2021). The results showed that the tangential distortion is not relevant and, therefore, negligible in a calibration. The principal distance was determined to be $\approx 142.06 \mathrm{~mm}$ at a fixed focus distance of about $4.5 \mathrm{~m}$, which is close to the nominal focal length of $138 \mathrm{~mm}$ (Table 1).

The calibration in the lab confirms the high optical quality of the lens system. However, the parameters cannot simply be applied to the digitisation station. Since the different camera body and different focus and aperture settings had to be used, the parameters do not describe the later-used camera-lens combination and shooting conditions during image capture on the digitisation stand. For the removal of distortions introduced during digitisation from the images, the camera must be calibrated in situ, to guarantee that the calibration is done under identical operating conditions.

\subsection{In Situ Calibration}

The standard set of the Brown model, as implemented in Agisoft Metashape version 1.6.4, was used for the in situ calibration of the phase one camera. The estimated calibration parameters are seen in Table 3.

Due to the very narrow depth of field on the copy stand, a flat test field was used to calibrate the camera. The test field could be tilted a few centimetres and rotated to determine the interior orientation parameters appropriately.

The results of the in situ calibration fit well with the results of the lab calibration. The maximum radial distortion is calibrated at $\approx 4$ pix. Tangential distortion is around $\approx 0.2$ pix. As expected, the use of a flat test field and small variations in depth lead to a less accurate determination of the principal distance, as seen in the standard error. Interestingly, the calibrated principal distance also deviates substantially, 17\% from the nominal focal length and $\sim 14 \%$ from the calibrated principal distance from the lab calibration.
Table 3 In situ camera calibration parameters

\begin{tabular}{lcl}
\hline & \multicolumn{1}{l}{ Value } & Std. error \\
\hline$c[\mathrm{~mm}]$ & 161.7560 & 0.0426 \\
$c_{\mathrm{X}}[\mathrm{mm}]$ & 0.0269 & 0.0034 \\
$c_{\mathrm{y}}[\mathrm{mm}]$ & 0.0563 & 0.0033 \\
$k_{1}$ & $-3.75694 \mathrm{e}-07$ & $1.09016 \mathrm{e}-08$ \\
$k_{2}$ & $-1.54871 \mathrm{e}-10$ & $1.66248 \mathrm{e}-11$ \\
$k_{3}$ & $6.27723 \mathrm{e}-14$ & $9.79517 \mathrm{e}-15$ \\
$p_{1}$ & $-3.78939 \mathrm{e}-07$ & $3.06113 \mathrm{e}-08$ \\
$p_{2}$ & $6.69559 \mathrm{e}-07$ & $2.48458 \mathrm{e}-08$ \\
\hline
\end{tabular}

This phenomenon can, however, be explained by the short focusing distance and thin lens equation (Eq. 2). By roughly approximating the unknown distance to the lens node with the distance between lens and light table $(a=93 \mathrm{~cm})$ and focal length $\left(f^{\prime}=138 \mathrm{~mm}\right)$, the image distance $a^{\prime}$ is approximated as $162 \mathrm{~mm}$ which agrees very well with the calibrated camera constant.

Apart from the expected high correlations between the radial distortion terms with each other $\left(k_{1}, k_{2}, k_{3}\right)$ and correlations of the tangential distortion parameters P1 and P2 with the principal point, no correlations between other parameters were observed. Since the tangential distortion is not significant, it could be removed from the bundle adjustment and correlations with the principal point would be irrelevant.

After calibration of the camera, a new set of images was created by correcting the original images with the determined interior orientation parameters of the digitising camera. Thus, the new set should not include the introduced effects of the lens distortion from digitising camera anymore, but only the original geometry from analogue camera.

\subsection{Evaluation of In Situ Calibration from Airborne Test Site Data}

To validate the influence of distortion in later processing, pre-corrected and non-corrected images were compared. Using the in situ calibration parameters, a distortion correction is applied to digitised images of an analogue image flight from the DGPF digital camera evaluation test over the test site Vaihingen/Enz (Cramer 2010). Several digital cameras have been flown in this test site as part of the project; two flights were made with analogue RMK-Top 15 camera for comparison only. The images of one of these RMK flights are considered here (Table 4). As the original colour negative film is still available, the analogue images have been re-scanned with the Phase One digitisation station. Now, two sets of digitised images from the same film negatives are available as depicted in Table 2 already. As already mentioned, the Phase One scanned images are used 
Table 4 Flight data of the RMK flight in the Vaihingen/Enz test site

\begin{tabular}{ll}
\hline Camera: & Intergraph RMK-TOP 15 \\
\hline Focal length & $c=154 \mathrm{~mm}$ \\
Film & Agfa X-100 Colour-negative \\
Date of flight & 24.07 .2008 \\
Absolute height & $\sim 1170 \mathrm{~m}$ \\
Height above ground & $\sim 870 \mathrm{~m}$ \\
Average scale & $1: 5660$ \\
In-flight overlap & $60 \%$ \\
Across-flight overlap & $70 \%$ \\
Number of images & 80 \\
\hline
\end{tabular}

as a non-corrected and an a priori distortion corrected set. This finally results in three different sets of scanned images from the same original analogue film.

Several aerotriangulations were calculated using each of these datasets. As the Vaihingen/Enz test site offers more than 150 signalised and precisely coordinated ground points, a large number can be used as independent check points to evaluate the accuracy of $3 \mathrm{D}$ object points after bundle adjustment. All AT runs are based on indirect georeferencing using a sufficiently high number of control points only. About 100 ground control points (GCP) were used, leaving another 50 points for independent check points (ChP). Self-calibrating additional parameters (AP) from Ebner (12 parameter) or Grün (44 parameters) are optionally considered to compensate for remaining systematic errors in the bundle. Processing was done with Trimble inpho Match-AT software. The geometric accuracy of check points from a priori distortion corrected imagery was compared with the results of using the original, uncorrected images and finally compared to the results using scanned images from the Z/I Imaging Photoscan 2001. The results are listed in Table 5.

Using in situ calibration data to rectify scanned images before AT, results in a marked improvement when no further mathematical model is applied during AT. However, the accuracy does not improve as much, compared to the 44-parameter model with uncorrected images. Obviously the a priori distortion correction results in effects, which are not fully compensated by traditional 12 and 44 AP sets. Overall, applying further mathematical models to the pre-corrected images does not seem to improve accuracy any further than that already achieved using no AP model. This is different to the case when using the non-corrected images and the images obtained from photogrammetric scanner digitisation, where significant improvements in geometric accuracy were obtained. The results underscore the non-triviality of superimposed image distortion and their effect on the accuracy that can be reached. As mentioned before, the slightly lower overall accuracy of the case using pre-corrected images indicate that some effects may not have been considered and/ or have been introduced by the image rectification. Further analysis is, therefore, recommended.

Based on the achieved geometric accuracies of this aerotriangulation set, a rough estimate can be made for the accuracies expected in processed orthophotos. Neglecting other error sources, it would take an inaccuracy of $5 \times$ the GSD horizontal and 7.5× GSD vertical in the case of $40 \mathrm{~cm}$ orthophotos before the requirements of $2 \mathrm{~m} / 3 \mathrm{~m}$ positional accuracy would be exceeded. Looking at the least favourable case (no APs, no a priori corrections), the horizontal and vertical accuracy of the aerotriangulation lies well below this requirement. As the orthophoto production was beyond the scope of this investigation, this aspect should be explored in more detail in future studies.
Table 5 Accuracy of bundle adjustment from check point residuals

\begin{tabular}{|c|c|c|c|c|c|c|c|c|}
\hline \multirow[t]{2}{*}{$\begin{array}{l}\text { Additional } \\
\text { parameters }\end{array}$} & \multirow[t]{2}{*}{$\mathrm{GCP} / \mathrm{ChP}$} & \multirow[t]{2}{*}{$\sigma_{0}[\mu \mathrm{m}] / \sigma_{0}[\mathrm{px}]$} & \multicolumn{3}{|c|}{ RMSE ChP [m] } & \multicolumn{3}{|c|}{$\begin{array}{l}\text { RMSE ChP [\% } \\
\text { of GSD] }\end{array}$} \\
\hline & & & $\Delta X$ & $\Delta Y$ & $\Delta Z$ & $\Delta X$ & $\Delta Y$ & $\Delta Z$ \\
\hline \multicolumn{9}{|c|}{ Z/I Imaging Photoscan 2001} \\
\hline No AP & $101 / 55$ & $3.90 / 0.2787$ & 0.039 & 0.033 & 0.092 & 49 & 41 & 115 \\
\hline $12 \mathrm{AP}$ & $101 / 55$ & $3.17 / 0.2267$ & 0.020 & 0.020 & 0.037 & 25 & 25 & 46 \\
\hline $44 \mathrm{AP}$ & $101 / 55$ & $3.17 / 0.2267$ & 0.020 & 0.020 & 0.037 & 25 & 25 & 46 \\
\hline \multicolumn{9}{|c|}{ Phase One iXM-MV150 (original images) } \\
\hline No AP & $98 / 55$ & $6.85 / 0.3019$ & 0.051 & 0.063 & 0.355 & 39 & 48 & 273 \\
\hline $12 \mathrm{AP}$ & $98 / 55$ & $6.47 / 0.2848$ & 0.042 & 0.061 & 0.257 & 32 & 47 & 198 \\
\hline $44 \mathrm{AP}$ & $98 / 55$ & $5.30 / 0.2335$ & 0.037 & 0.037 & 0.067 & 28 & 28 & 52 \\
\hline \multicolumn{9}{|c|}{ Phase One iXM-MV150 (a priori distortion correction) } \\
\hline No AP & $98 / 55$ & $7.1 / 0.3128$ & 0.048 & 0.040 & 0.085 & 37 & 31 & 65 \\
\hline $12 \mathrm{AP}$ & $98 / 55$ & $6.7 / 0.2952$ & 0.040 & 0.042 & 0.092 & 31 & 32 & 71 \\
\hline $44 \mathrm{AP}$ & $98 / 55$ & $6.1 / 0.2729$ & 0.043 & 0.043 & 0.084 & 33 & 33 & 65 \\
\hline
\end{tabular}




\section{Conclusion}

The empirical investigations into the geometric resolution and geometric accuracy of the Phase One scan station used at the LGL-BW to digitise historical images show that the performance of a dedicated (1st generation) photogrammetric scanner is not reached with the current status of this system.

Nevertheless, the positional accuracy of produced orthophotos should comfortably lie within the accuracy requirements of $2 \mathrm{~m}$ standard deviation set out for this particular project. Even if uncorrected images are used, introduced effects attributable to the digitisation method are currently not regarded as pivotal and with further mathematical or a priori corrections their impact would be reduced even further.

However, a few important aspects should be taken into consideration. As already mentioned, geometric accuracy and especially resolution that is inherent in the analogue image but lost during the digitisation step, is practically impossible to regain later. This is a general concern regarding all analogue to digital conversions, and in the specific case of photogrammetry, additional artefacts, distortions, and loss of spatial resolution should ideally be kept to a minimum in the digital master copy.

The superimposed distortion profiles are not trivial to separate and correct afterwards. It cannot be ruled out that the additional processing of distortion correction introduces further sources of errors, limiting the geometric accuracy that can finally be reached.

Furthermore, some practical issues should also be addressed in future iterations to improve the quality in terms of long-term repeatability and stability of the digitisation process. Focusing of the lens is currently a manual process using a live feed of the camera with reduced resolution. Accurate focus adjustment is, therefore, a time-consuming process with limited repeatability in achieving the same focus setting. Since the parallelism of camera and image plane has to be checked and adjusted as well, changing the focus is currently unavoidable. To limit further effects, such as vibrations and other movements, further dampening and improvements of the stability of the physical system should also be considered. These influences currently impact the long-term ability to digitise with stable imaging conditions.

Finally, whilst the development of new camera-based digitising methods is important and needed, considering how many aerial photos are still not digitised, these current constraints must be considered in applications with higher accuracy requirements. As an example, cadastral photogrammetry should be mentioned, which has gained in importance recently. Readjustment of the old cadastral blocks from the 1970/80s, based control points re-measured with GNSS allow the adjusted coordinates to be obtained in current reference coordinate frames, circumventing any transformation from former historic coordinate frames like Soldner coordinates, which were common in Baden-Württemberg at that time. For these applications, standardised and tested photogrammetric scanners should continue to be used for digitisation, until more precise camera-based scanning stations become available.

Acknowledgements Special thanks are extended to the Landesamt für Geoinformation und Landentwicklung of Baden-Württemberg for their support and availability of the digitisation station, and to the Landesamt für Digitalisierung, Breitband und Vermessung of Bavaria for providing support with the calculation of aerotriangulations. Further thanks are also extended to Henry Meißner, who kindly provided the software and Siemens star template. The camera body used in the test field calibration was kindly provided by Phase One A/S. Wolfgang Aleithe kindly provided the image shown in Fig. 1.

Funding Open Access funding enabled and organized by Projekt DEAL.

Open Access This article is licensed under a Creative Commons Attribution 4.0 International License, which permits use, sharing, adaptation, distribution and reproduction in any medium or format, as long as you give appropriate credit to the original author(s) and the source, provide a link to the Creative Commons licence, and indicate if changes were made. The images or other third party material in this article are included in the article's Creative Commons licence, unless indicated otherwise in a credit line to the material. If material is not included in the article's Creative Commons licence and your intended use is not permitted by statutory regulation or exceeds the permitted use, you will need to obtain permission directly from the copyright holder. To view a copy of this licence, visit http://creativecommons.org/licenses/by/4.0/.

\section{References}

Aleithe W (2021) Personal communication. Accessed 5 Sept 2021

Baltsavias EP, Crosetto M (1996) Test and calibration of a DTP scanner for GIS data acquisition. In: Mussio L, Forlani G, Crosilla F (eds) Data acquisition and analysis for multimedia GIS. Springer Vienna, Vienna, pp 141-150

Baltsavias EP, Kaeser C (1999) Quality evaluation of the DSW200, DSW300, SCAI and OrthoVision photogrammetric scanners. In: Kölbl O (ed) Proceedings of the OEEPE-workshop on automation in digital photogrammetric production, vol 37. Marne la Valée, 22.-24. Juni 1999. European Organization for Experimental Photogrammetric Research. Bundesamt für Kartographie und Geodäsie (Official Publications, 37), Frankfurt am Main, pp $111-134$

Baltsavias EP, Häring S, Kersten T (1997) Geometric and radiometric performance evaluation of the Leica/Helava DSW200 photogrammetric film scanner

Baltsavias E, Waegli B (1996) Quality analysis and calibration of DTP scanners. XVIII ISPRS Congr 31(31):13-19. https://doi.org/10. 3929/ethz-a-004333744

Baltsavias EP (1998) Photogrammetric scanners: survey, technological developments and requirements. With assistance of Eidgenössische Technische Hochschule Zürich Institut Für Geodäsie Und Photogrammetrie 
Baltsavias EP (1999) On the performance of photogrammetric scanners. In: Fritsch D, Spiller R (eds) Photogrammetric Week '99. Wichmann Verlag, pp 155-174. https://phowo.ifp.uni-stuttgart. de/publications/phowo99/baltsavias99.pdf

Brown DC (1971) Close-range camera calibration. Photogramm Eng 37(8):855-866

Brown DC (1966) Decentering distortion of lenses. Photogramm Eng 32(3):444-462. https://web.achive.org/web/20180312205006/ https://www.asprs.org/wp-content/uploads/pers/1966journal/may/ 1966_may_444-462.pdf

Cowley DC, Stichelbaut BB (2012) Historic aerial photographic archives for European archaeology. Eur J Archaeol 15(2):217236. https://doi.org/10.1179/1461957112Y.0000000010

Cramer M (2010) The DGPF-test on digital airborne camera evaluation overview and test design. PFG 2010(2):73-82. https://doi.org/10. 1127/1432-8364/2010/0041

Cramer M, Zhang S, Meißner H, Reulke R (2020) Quality assessment of high-resolution UAV imagery and products. In: Publikationen der DGPF, vol. 29. 40. Wissenschaftlich-Technische Jahrestagung der DGPF. München, 4.-6. März 2020. Deutsche Gesellschaft für Photogrammetrie, Fernerkundung und Geoinformation. München (29), pp 33-46. https://www.tib.eu/de/suchen/id/TIBKAT\%3A169 4344428

Deutsches Institut für Normung (DIN) (2017) DIN 18716:2017-06, Photogrammetrie und Fernerkundung_- Begriffe

Ebner H (1976) Self calibrating block adjustment. In Bildmessung und Luftbildwessen 44, pp 128-139. https://ifpwww.ifp.uni-stuttgart. de/publications/-1980/1976-Ebner-Self_Calibration_Block_Adjus tment.pdf

Fraser CS, Brown DC (1986) Industrial photogrammetry: new developments and recent applications. Photogram Rec 12:197-217. https://doi.org/10.1111/j.1477-9730.1986.tb00557.x

GeoDyn (2021) The PromptSCAN product line. https://www.geodyn. com/promptscan.html. Accessed 6 Sept 2021

Giordano S, Mallet C (2019) Archiving and geoprocessing of historical aerial images: current status in Europe. European Spatial Data Research (EuroSDR). Wien, Österreich (Official Publications, 70). https://www.eurosdr.net/sites/default/files/uploaded_files/eurosdr_ publication_ndeg_70.pdf

Grün A (1978) Experiences with self-calibrating bundle adjustments. In: ACSM-ASP. Washington D.C. https://www.yumpu.com/en/ document/read/22487342/experiences-with-self-calibrating-bundle-adjustment-idb

Herbst T (2020) Historische Luftbilder im Digitalen Luftbildatlas BW-Zeitzeugen aus der Vogelperspektive. In: DVW-BW (01). https://www.lgl-bw.de/export/sites/lgl/unsere-themen/Geoinforma tion/Publikationen/Galerien/Dokumente/DVW-BW-Heft-1-2020Herbst.pdf. Accessed 23 Sept 2020
Herbst T (2021) Ein analoges Archiv wird digital-Am Beispiel des Projektes Digitaler Luftbildatlas BW. Jahrestagung der Deutschen Gesellschaft für Photogrammetrie, Fernerkundung und Geoinformation e.V (DGPF). Accessed 11 Mar 2021

Kalinowski P, Both F, Luhmann T, Warnke U (2021) Data fusion of historical photographs with modern 3D data for an archaeological excavation-concept and first results. In: The international archives of the photogrammetry, remote sensing and spatial information sciences. XXIV ISPRS congress imaging today, foreseeing tomorrow, commission II-2021 edition, 5-9 July 2021: Copernicus GmbH (XLIII-B2-2021), pp 571-576. https://www.int-archphotogramm-remote-sens-spatial-inf-sci.net/XLIII-B2-2021/571/ 2021/. Accessed 28 June 2021

Kopp H (2021) Warum Filme von Filmbelichtung24.de. https://www. filmbelichtung24.de/warum-filmbelichtung24de.html. Accessed 9 Sept 2021

Kraus K (2007) Photogrammetry. Geometry from images and laser scans, 2nd edn. De Gruyter, Berlin

Luhmann T, Robson S, Kyle S, Böhm J (2020) Close-range photogrammetry and 3D imaging, 3rd edn. De Gruyter, Berlin

Luhmann T, Wester-Ebbinghaus W (1986) Rolleimetric RS-a new digital image processing system. In: Int. Arch. photogrammetry \& rem. sensing, ISPRS symposium comm. II, Baltimore, pp $110-119$

Meißner H (2021) Determination and improvement of spatial resolution obtained by optical remote sensing systems. Dissertation. Humboldt-Universität zu Berlin, Berlin. Institut für Informatik

National Collection of Aerial Photography (2021) NCAP digital imaging facilities I NCAP-National Collection of Aerial Photography. https://ncap.org.uk/about-ncap/our-work/digital-imaging-facil ities. Accessed 28 July 2021

Pedrotti FL, Pedrotti LS, Bausch W, Schmidt H (2005) Optik für Ingenieure. Grundlagen; mit 28 Tabellen. 3., bearb. und aktualisierte Aufl. Springer, Berlin

Schulz J (2021) Qualitätsuntersuchung der Phase One iXM-MV150F Dokumentenkamera für die Luftbilddigitalisierung. MSc Thesis. Universität Stuttgart, Stuttgart, Germany. Institut für Photogrammetrie

Truquin P (2019) Geoprocessing, Archiving \& Sharing Historical Aerial Images. Institut National de L'Information Geographique et Forestiére (IGN). EuroSDR Workshop on Geoprocessing and Archiving of Historical Aerial Images. European Spatial Data Research (EuroSDR), 6/3/2019. Available online at https://www. eurosdr.net/sites/default/files/images/inline/05_truquin_france.pdf

Vexel Imaging GmbH (2008) UltraScan 5000: Precision Photogrammetic Scanning. Brochure. Available online at https://ecogis.pl/ PDF/USCAN.pdf 